\title{
TRAIT-MEDIATED INDIRECT EFFECTS IN LARVAL ANURANS: REVERSING COMPETITION WITH THE THREAT OF PREDATION
}

\author{
RiCK A. RELYEA ${ }^{1}$ \\ Department of Biology, University of Michigan, Ann Arbor, Michigan 48109 USA
}

\begin{abstract}
Ecologists recently have been focusing on the role that trait-mediated indirect effects can have on community structure and composition. To date, this work has primarily focused on the effects of predator-induced behavioral plasticity on communities. However, predator-induced morphological plasticity, which has been documented in many taxa, might also lead to trait-mediated indirect effects. Here, I examined how predators altered the behavior and morphology of larval wood frogs (Rana sylvatica) and leopard frogs ( $R$. pipiens) and how these phenotypic changes altered the outcome of competition between the two species.

Competition in the absence of caged predators was asymmetric; when reared separately, leopard frogs grew more than wood frogs, but when competing (without predators), wood frogs grew faster than leopard frogs. The presence of caged predators reversed the outcome of competition between the two anuran prey. In the presence of larval dragonflies (Anax spp.) or caged mudminnows (Umbra limi), leopard frogs grew faster than wood frogs while total tadpole biomass production remained unchanged. Thus, there was a predator-mediated indirect effect.

Because predators alter both the behavior and morphology of larval anurans and both of these traits are known to affect resource consumption and growth, both are potential mechanisms to explain the change in competitive outcome. Changes in behavior were not related to changes in growth, but changes in morphology (specifically mouth width and tail length) were related to changes in growth. When competitors were added (without predators), wood frogs increased their mouth width by $10 \%$ and their tail length by $3 \%$, while leopard frogs increased their mouth width by $5 \%$ and did not change their tail length. The greater increase in mouth width for wood frogs should increase their forage intake, since tadpoles feed by scraping periphyton; the importance of a $3 \%$ longer tail in competitive ability is unknown. The presence of the predator threat (via chemical cues from the caged predators) reduced both the mouth width and tail length in the two prey species to precompetition levels. This response corresponded with the reduced competitive ability of the wood frogs. This work demonstrates that both competitors and predators can alter prey morphology and suggests that changes in morphology can cause trait-mediated indirect effects.
\end{abstract}

Key words: Anax; behavior; competition; leopard frog; morphology; phenotypic plasticity; predation; Rana pipiens; Rana sylvatica; Umbra limi; wood frog.

\section{INTRODUCTION}

Ecological communities are influenced by numerous direct and indirect effects among species, and these effects collectively determine community composition and structure. Historically, ecologists have concentrated on direct and indirect interactions in which one species changes the density of another species in a food web (e.g., top-down and bottom-up trophic cascades, see Hunter and Price 1992, Power 1992, Strong 1992). More recently, we have begun to appreciate that species also can change the traits of another species in a food web. Because species' traits determine how species interact with other taxa in the community (e.g., compet-

Manuscript received 5 October 1998; revised 10 July 1999; accepted 12 July 1999; final version received 20 September 1999.

${ }^{1}$ Present address: Department of Biological Sciences, University of Pittsburgh, Pittsburgh, Pennsylvania 15260 USA. E-mail: relyea@pitt.edu itive ability or predator resistance ability), changing another species' traits can have an indirect effect on how that species subsequently interacts with other taxa. Thus, changes in traits that alter interaction rates have been termed trait-mediated indirect effects (Abrams 1995).

The probable importance of trait-mediated indirect effects in structuring ecological communities was first described by Abrams (1983). Werner (1992b) subsequently argued that predator-induced changes in prey behavior (e.g., foraging activity and spatial distribution) are one type of trait change that should lead to widespread and complex trait-mediated indirect effects in ecological communities. To date, empirical work on trait-mediated indirect effects has focused on changes in prey behavior. In many simple, three-species systems, prey reduce activity or increase refuge use in the presence of predators, resulting in decreased prey consumption of food (Turner and Mittelbach 1990, Skelly 
1992, Wissinger and McGrady 1993, Diehl and Eklöv 1995, Schmitz et al. 1997). However, in more complex systems, nonlethal effects of predators on prey can be transmitted through the food web with a variety of results (Wootton 1992, Persson and Eklöv 1995, Werner and Anholt 1996, Peacor and Werner 1997). For example, a predator-induced reduction in foraging activity will have a positive indirect effect on resources and, hence, also on competitors of the prey (Werner and Anholt 1996, Peacor and Werner 1997). At the same time, the addition of a competitor can reduce resources and cause individuals to increase their foraging activity and become more susceptible to predation (Peacor and Werner 1997). Thus, behaviorallymediated indirect effects in simple food webs can have far-reaching, complex effects on the community.

While a growing body of evidence suggests that behavioral plasticity can lead to trait-mediated indirect effects, there is no inherent reason that trait-mediated indirect effects should be limited to behavior. Morphology also can be highly plastic and may also cause trait-mediated indirect effects. For example, if a change in morphology makes prey less vulnerable to predation at the cost of a reduced ability to harvest resources, then, in the presence of a predator, mortality risk should shift to alternative prey. Concurrently, the reduced ability to harvest resources should have a positive indirect effect on the competitors of the prey. Morphological plasticity has been frequently observed in plants responding to herbivores (Karban and Baldwin 1997) and in many groups of animals responding to predators, including protists, rotifers, crustaceans, bryozoans, and gastropods (see reviews by Havel 1987, Sih 1987, Harvell 1990).

While we are rapidly accumulating examples of animals altering their morphology in the presence of predators, we have few examples of animals altering their morphology in the presence of competitors. This is most likely due to a lack of investigation rather than a lack of occurrence. Competitor-induced morphology has been described in several colonial marine organisms (Harvell 1990) and in a few species of larval amphibians that inhabit highly ephemeral habitats and develop carnivorous phenotypes in the presence of increased competition (Pfennig 1992a, b, Reilly et al. 1992, Collins and Pfennig 1993). Whether other larval anurans alter their morphology in response to competition remains unknown.

I used a system of larval amphibians to examine how competition and the threat of predation alters the morphology of two larval anuran prey and whether the changes in morphology are related to changes in the competitive outcome between the two anurans. Larval anurans exhibit morphological plasticity in the presence of predators (Smith and Van Buskirk 1995, McCollum and Van Buskirk 1996, McCollum and Leimberger 1997, Van Buskirk et al. 1997, Van Buskirk and Relyea 1998). For example, several species de- velop a deeper tail fin and a smaller body in the presence of caged (nonlethal) aeshnid dragonflies. Tadpoles with predator-induced morphology are less vulnerable to predation but suffer lower growth rates (Van Buskirk and Relyea 1998). While the presence of predators can alter tadpole morphology in a fashion that reduces their growth rate, it is unknown whether the reduced growth rate can indirectly affect other species in the community that harvest some of the same resources. To test this hypothesis, I measured morphological and growth responses of wood frogs and leopard frogs in a field experiment, rearing them separately, in competition with each other, and in competition with caged (nonlethal) predators present. In addition, I quantified behavioral responses of the prey to caged predators to determine if the change in competitive outcome was associated with changes in larval behavior.

\section{Methods}

To quantify behavioral and morphological responses of larval anurans and the effect these responses have on competitive ability, I conducted both a laboratory experiment and a field experiment using larval wood frogs (Rana sylvatica) and leopard frogs ( $R$. pipiens). Wood frogs are characteristic of small woodland ponds but also are found in larger marshes that dry frequently enough to exclude fish. The latter habitats can have a high density of invertebrate predators including aeshnid dragonflies. Only occasionally do wood frogs overlap with fish. In comparison, leopard frogs are characteristic of temporary open-meadow ponds and permanent ponds that contain small gape-limited fish (cyprinids, umbrids, and gasterosteids) as well as many invertebrate predators including aeshnid dragonflies. These two anuran species sometimes overlap and have the potential to compete in the larval stage (DeBenedictis 1974, Collins and Wilbur 1979, Skelly et al. 1999, Werner and Glennemeier 1999). In all experiments, newly hatched tadpoles were selected from a mixture of $>10$ egg masses and all animals were collected on the Edwin S. George Reserve (ESGR) in southeast Michigan, USA.

\section{Laboratory experiment}

The laboratory experiment was conducted to quantify how larvae of the two species altered their behavior in the presence of predators. I collected wood frog and leopard frog egg masses on 7 April and 27 April 1994, respectively, and hatched them in outdoor wading pools containing well water; thus, the tadpoles remained predator-naive. Wood frog eggs were collected from Buffer Zone Marsh and West Marsh whereas leopard frog eggs were collected from Southwest Swamp. All three wetlands contain aeshnid dragonflies and two of the three contain predatory fish. For each species, groups of ten tadpoles were placed into plastic, rectangular tubs containing $7 \mathrm{~L}$ of aged well water (changed weekly) and arranged on two shelves in a 
randomized block design with each shelf serving as a block that contained two replicates of each treatment. Tubs were placed under a bank of fluorescent lights on a 14:10-hr light:dark schedule. Because wood frogs breed 1-2 weeks earlier than leopard frogs, the wood frog laboratory experiment was initiated one week earlier than the leopard frog laboratory experiment so that tadpoles similar in size and age could be used in the experiment.

For each anuran species, I randomly assigned one of three treatments to the tubs: an empty cage (control), a caged dragonfly larva (Anax sp.), or a caged mudminnow (Umbra limi). These environments represent realistic predator environments found along the gradient of pond hydroperiod that these two anurans live in. Cages were constructed of two wooden slats that suspended a bag made from mosquito netting and were placed into one end of each tub. Tadpoles can detect waterborne chemical cues that are produced by predators (Petranka et al. 1987, Kats et al. 1988, McCollum and Leimberger 1997) and this allowed me to simulate the threat of predation to induce behavioral changes in tadpoles while preventing actual predation. I fed tadpoles and their predators three times per week for five weeks. At each feeding, tadpoles were fed a 3:1 mixture of Purina rabbit chow (Ralston Purina, St. Louis, Missouri, USA) and Tetramin fish flakes (Tetra, Blacksburg, Virginia, USA) at a rate of $6 \%$ of body mass per day and predators were fed approximately $100 \mathrm{mg}$ of tadpoles of the same species that was placed in the tub.

During the five-week period, I made behavioral observations of the tadpoles to quantify their activity and spatial responses to the caged predators. I quantified activity by scan sampling (Altmann 1974) the tubs and calculated the proportion of tadpoles in a tub that were moving. To quantify spatial avoidance, I drew a line down the middle of the tub and quantified the proportion of tadpoles that were on the side containing the predator cage. I observed wood frogs 38 times and leopard frogs 28 times during all daylight hours (determined haphazardly) and used the mean activity and spatial distribution for each tub as a single replicate. The relative magnitude of response to the predator environments remained constant over time, suggesting there was no habituation to the predator environments over time. The two behavioral responses were analyzed as a multivariate analysis of variance (MANOVA) with anuran species and predator treatments as main effects. The response residuals met MANOVA assumptions; therefore, the data were not transformed. When significant multivariate effects were found, I then examined the univariate responses for significant effects.

\section{Field experiment}

Wood frog eggs for the field experiment were collected from Buffer Zone Marsh on 31 March 1995 and kept in outdoor wading pools containing well water until they hatched $(\sim 3 \mathrm{wk})$. Leopard frog eggs were collected from Fishhook Marsh on 20 April 1995 and kept in the laboratory to accelerate hatching ( $4 \mathrm{~d}$ at $25^{\circ} \mathrm{C}$ ) so that the two anuran species were similar in size when the field experiment began. Umbra predators were dipnetted and seined from Crane Pond and Anax predators were dipnetted from a set of experimental ponds.

The field experiment was conducted in screened pens placed in a ten-yr-old experimental pond located at the Experimental Pond Facility on the ESGR. This pond contained larval dragonflies but no fish. The pens were $1.5 \times 1.0 \times 0.8 \mathrm{~m}$, constructed from $5 \times 5 \mathrm{~cm}$ lumber, and covered with 0.25 -mm nylon mesh to exclude predators and other amphibians. This fine-mesh screening rapidly becomes colonized by periphyton which greatly restricts water flow, thus reducing predator cues from neighboring pens as well as predator cues from the pond. Aluminum window screening was placed on the bottom of each pen to protect the nylon mesh. Pens were placed in the littoral zone of the pond (perpendicular to the shore) on 2 May 1995 and $300 \mathrm{~g}$ of leaves (primarily Quercus spp.) were added to serve as a substrate and nutrient source for periphyton growth.

Each pen was equipped with three small Anax cages and one large fish cage. I caged Anax separately because they are cannibalistic; in contrast, fish survive better when caged together. I constructed Anax cages of $10 \times 10 \mathrm{~cm}$ plastic drain pipe and covered the ends with $1 \times 2 \mathrm{~mm}$ fiberglass screening. A small piece of polystyrene $\left(16 \mathrm{~cm}^{3}\right)$ was added to each cage to make it float. The fish cage was constructed of nylon screening (cage dimensions $1.0 \times 0.8 \times 0.3 \mathrm{~m} ; 0.25-\mathrm{mm}$ mesh) folded into a bag. A hoop of black plastic pipe filled with sand was added to each fish cage to ensure the cage remained expanded. I placed the Anax cages in the shallow end of the pen and the fish bag in the deep end of the pen; this corresponds to the relative depth distributions of these predators in natural ponds.

I employed a randomized block design with four spatial blocks (i.e., replicates) arrayed around the pond. Within each block, I randomly assigned six treatments. The first three treatments were designed to demonstrate that wood frogs and leopard frogs were competing in the absence of predators; the three treatments consisted of 50 (33 frogs $\left./ \mathrm{m}^{2}\right)$ wood frogs $(16.4 \pm 0.3 \mathrm{mg}$, mean $\pm 1 \mathrm{SE}), 50$ leopard frogs $(7.5 \pm 0.2 \mathrm{mg}$, mean \pm 1 $\mathrm{SE}$ ), and 50 wood frogs plus 50 leopard frogs. (The preceding values are an estimate of initial tadpole size based on a random sample of 20 tadpoles at the start of the experiment.) Natural densities of wood frogs range from 4 frogs $/ \mathrm{m}^{2}$ to $253 \mathrm{frogs} / \mathrm{m}^{2}$ (E. E. Werner, unpublished data). The final three treatments reared the two anurans together with caged (nonlethal) predators to determine if the nonlethal presence of predators affected the competitive outcome. Predator treatments were either the presence of three $\left(1.5\right.$ Anax $\left./ \mathrm{m}^{2}\right)$ lateinstar Anax, three adult Umbra (standard length $=7.2$ $\pm 0.2 \mathrm{~cm}$, mean $\pm 1 \mathrm{SE}$ ), or three Anax plus three 
Umbra. These densities of predators are within natural predator densities (aeshnid density $=0.2-4.1$ individuals $/ \mathrm{m}^{2}$, Umbra density $=0.5-10.5$ individuals $/ \mathrm{m}^{2}$; E. E. Werner, unpublished data). All tadpoles and predators were added to the pens on 5 May 1995. At the initiation of the experiment, I set aside two samples of 50 tadpoles of each species to estimate mortality due to handling the tadpoles during the experimental set up. Survivorship after $48 \mathrm{hr}$ was $100 \%$ for both species.

I fed the predators in the field experiment three times per week. Anax were each fed 3-4 tadpoles of each anuran species. Each Umbra was fed 1-2 tadpoles of each anuran species as well as one small earthworm. I added earthworms to supplement the fish diet and increase fish survivorship because many larval anurans are not readily consumed by fish (Kruse and Francis 1977, Kats et al. 1988, Werner and McPeek 1994). Other experiments have demonstrated that wood frogs are $100 \%$ palatable to Umbra but leopard frogs are rejected by Umbra half of the time (Relyea, unpublished manuscript). Empty cages were lifted up out of the water three times per week to equalize disturbance among treatments. During the field experiment, behavioral observations were attempted but the water in the pond was not clear enough to quantify behavior.

The field experiment was terminated after one month, when hind legs appeared on the wood frogs, indicating impending metamorphosis. Two blocks were terminated on 5 June 1995 and two blocks were terminated on 6 June 1995. All leaves and animals were removed from the pens and the anuran larvae were sorted from the leaves. Larvae were then counted and weighed. For each species, I used the survivorship of tadpoles and the mean mass gained from each pen as response variables. To better understand the trait-mediated indirect effects, I also calculated the total biomass produced in a pen ([wood frog survivorship $\times$ mass gained per wood frog] + [leopard frog survivorship $\times$ mass gained per leopard frog]). This response allows one to demonstrate that the distribution of resources between competing prey can be altered while the total biomass produced in a pen remains constant. Such a result more clearly demonstrates the presence of a trait-mediated indirect effect.

I analyzed survivorship and growth of wood frogs and leopard frogs with a MANOVA with prey species and pen treatment as the main effects. In the analysis, I wanted to look for differences in growth and survival both among pen treatments and between prey species. While the experiment was designed with six treatments, wood frogs and leopard frogs were each only exposed to five of the treatments (leopard frogs were not in the wood-frogs-alone treatment and wood frogs were not in the leopard-frogs-alone treatment). Thus, I collapsed the six treatments into five treatments, considering the cases of each species alone as a single treatment crossed with two species of prey. This approach allowed me to compare the growth of the two species across five treatments (alone, together, together with Anax, together with Umbra, and together with Anax plus Umbra). The major comparisons of interest were to determine (1) if the addition of interspecific competitors (without predators) altered growth and survivorship relative to each species reared alone, and (2) to determine if any of the caged predators altered the outcome of this competition. The response residuals met the assumptions of normality and homoscedasticity; therefore, the data were not transformed. Block interactions were never significant and therefore were removed from the analyses. Two pens were excluded from the analyses. The first pen (wood frogs and leopard frogs reared with Anax plus Umbra) was blown out to the center of the pond by heavy winds and the larvae escaped. In the second pen (wood frogs and leopard frogs reared with Anax), an Anax escaped from its cage one week prior to termination and caused twice the mortality observed in the other three replicates.

I analyzed total biomass production as an ANOVA. Because both prey species were combined to derive this response, prey species was not an effect in this analysis. To examine patterns in biomass production, it would be incorrect to combine the two speciesreared-alone treatments since I was examining the amount of biomass produced in a single pen. Thus, there was a total of six treatments (wood frogs alone, leopard frogs alone, both frogs together, together with Anax, together with Umbra, and together with Anax plus Umbra).

A sample of 20 tadpoles per species from each pen was preserved in $10 \%$ formalin for measurement of morphology. I placed each preserved tadpole under a video camera connected to a computer. Using BioScan Optimas image analysis software (Optimas, Bothell, Washington, USA), I captured a digital image of the tadpole and then traced seven morphological dimensions. From the side view, I measured the maximum tail fin depth, maximum tail muscle depth, maximum tail length, maximum body length, and maximum body height (Fig. 1). A piece of flat glass was placed under the tadpole's tail so that the tadpole laid in a natural, undistorted plane. From the top view, I measured the maximum tail muscle width and maximum body width. I made two additional morphological measurements using a dissecting microscope equipped with an optical micrometer under $250 \times$ magnification. I measured the length of the longest denticle (tooth row), hereafter termed mouth width, and the maximum distance between the first denticle on the upper labium and the last denticle on the lower labium, hereafter termed mouth length (Fig. 1). All measurements were made with the mouth in its relaxed, preserved position.

To analyze tadpole morphology, I derived an estimate of overall tadpole size and then regressed all linear dimensions against overall size. This procedure (termed "shearing;" Bookstein 1991) allowed me to determine whether tadpoles differed in relative body 

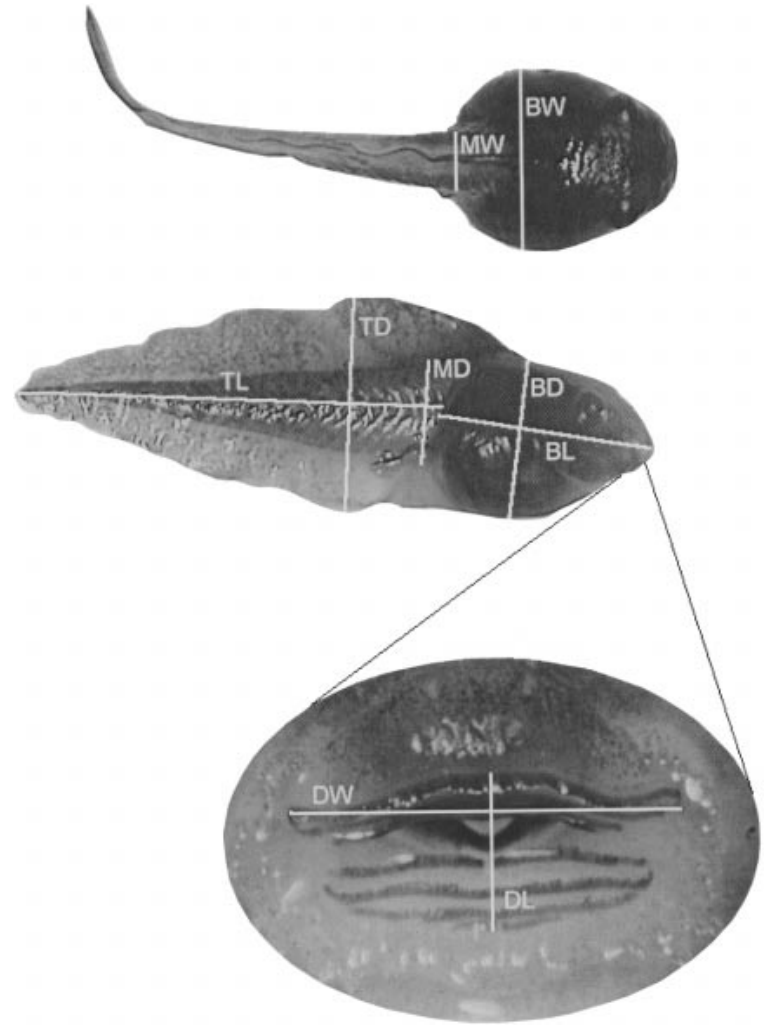

FIG. 1. A lateral view (top) and dorsal view (middle) of a wood frog tadpole and a ventral view of the mouth (bottom) showing the nine linear measures that were used in the analysis of morphological plasticity $(\mathrm{BD}=$ body depth, $\mathrm{BL}=$ body length, $\mathrm{BW}=$ body width, $\mathrm{TD}=$ tail depth, $\mathrm{TL}=$ tail length, $\mathrm{MD}=$ muscle depth, $\mathrm{MW}=$ muscle width, $\mathrm{DW}=$ denticle width, and DL $=$ denticle length).

and tail dimensions after accounting for differences in overall size. To estimate overall size, I first log-transformed all dimensions (to improve the linearity of the dimensions) and then entered them into a principle components analysis (PCA). I used the three dimensions of the body and the two dimensions of the tail fin in the PCA. All five dimension positively loaded $(>0.91)$ on the first principle component (PC-1), indicating that the PC-1 score was a good estimate of overall tadpole size. I then regressed all nine linear dimensions against PC-1 and saved the residuals from the regression. Mean residuals from each pen were then

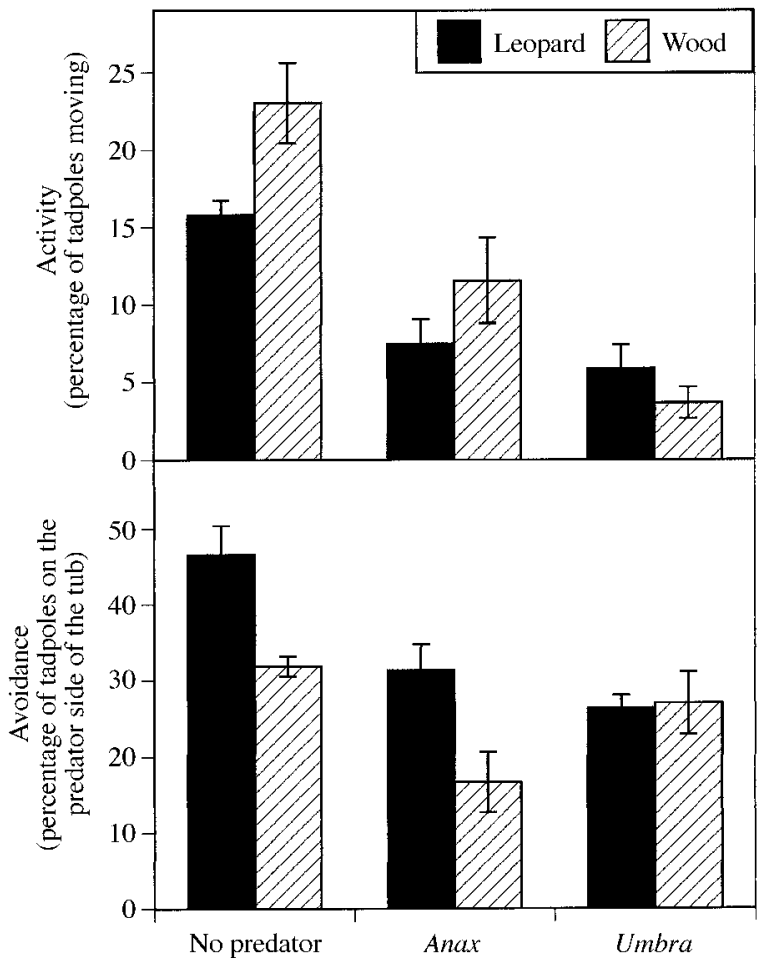

FIG. 2. Activity and spatial distribution of larval wood frogs and leopard frogs reared in the absence of predators, in the presence of caged Anax, and in the presence of caged Umbra. Activity was defined as the percentage of tadpoles that were moving, and spatial avoidance was defined as the percentage of individuals on the side of tub containing the caged predator. Data are means $\pm 1 \mathrm{SE}$.

analyzed with a MANOVA similar to the analysis of growth and survivorship, using the five pen treatments and two prey species as the main effects to determine whether the two species differed in how they responded to the pen treatments. All mean comparisons were conducted using Fisher's LSD test.

\section{RESUlts}

\section{Laboratory experiment}

Both wood frogs and leopard frogs altered their behavior in response to the caged predators (Table 1, Fig. $2)$. There were significant multivariate responses to predator environments, prey species, and their interaction. The univariate analysis of activity and the sub-

TABle 1. MANOVA results ( $P$ values) from the laboratory experiment investigating the effect of the absence or caged presence of Anax and Umbra on the activity and spatial distribution of larval wood frogs and leopard frogs reared separately.

\begin{tabular}{|c|c|c|c|c|c|c|}
\hline \multirow[b]{3}{*}{ Source } & \multirow{2}{*}{\multicolumn{2}{|c|}{ Wilks' Lambda multivariate test }} & \multicolumn{4}{|c|}{ Univariate tests } \\
\hline & & & \multicolumn{2}{|c|}{ Activity } & \multicolumn{2}{|c|}{ Spatial distribution } \\
\hline & $F(\mathrm{df})$ & $P$ & $F(\mathrm{df})$ & $P$ & $F(\mathrm{df})$ & $P$ \\
\hline Anuran species & $8.8(2,17)$ & 0.002 & $8.8(1,18)$ & 0.063 & $13.0(1,18)$ & 0.002 \\
\hline Predator & $13.4(4,34)$ & $<0.001$ & $31.8(2,18)$ & $<0.001$ & $12.5(1,18)$ & $<0.001$ \\
\hline Anuran $\times$ Predator & $3.1(4,34)$ & 0.026 & $3.3(2,18)$ & 0.060 & $3.7(2,18)$ & 0.045 \\
\hline
\end{tabular}


TABLE 2. Results of a MANOVA and ANOVAs for the survivorship and growth rate of larval wood frogs and leopard frogs reared in pond enclosures.

\begin{tabular}{|c|c|c|c|c|c|c|c|c|c|}
\hline \multirow[b]{2}{*}{ Source } & \multicolumn{3}{|c|}{$\begin{array}{l}\text { Wilks' Lambda } \\
\text { multivariate test }\end{array}$} & \multicolumn{3}{|c|}{ Univariate survivorship } & \multicolumn{3}{|c|}{ Univariate growth rate } \\
\hline & $\mathrm{df}$ & $F$ & $P$ & df & $F$ & $P$ & df & $F$ & $P$ \\
\hline Block & 6,44 & 2.2 & 0.057 & 3,23 & 1.0 & 0.399 & 3,23 & 3.6 & 0.028 \\
\hline Prey species & 2,22 & 12.8 & 0.008 & 1,23 & 7.7 & 0.011 & 1,23 & 13.4 & 0.001 \\
\hline Treatment & 8,44 & 9.2 & $<0.001$ & 4,23 & 0.6 & 0.643 & 4,23 & 29.7 & $<0.001$ \\
\hline Prey species $\times$ Treatment & 8,44 & 3.1 & 0.008 & 4,23 & 0.4 & 0.827 & 4,23 & 6.9 & 0.001 \\
\hline
\end{tabular}

sequent mean comparisons indicated that wood frogs reduced activity by $50 \%$ in the presence of $\operatorname{Anax}(P<$ $0.001)$ and by $84 \%$ in the presence of Umbra $(P<$ $0.001)$; the response to Umbra was stronger than the response to Anax $(P=0.008)$. Leopard frogs reduced activity by $53 \%$ in the presence of $\operatorname{Anax}(P=0.006)$ and by $63 \%$ in the presence of Umbra $(P=0.002)$; leopard frog activity was not different between predator treatments $(P=0.559)$. Comparing the two anuran species, wood frogs were more active than leopard frogs in the absence of predators $(P=0.014)$ but they did not differ in activity when $\operatorname{Anax}(P=0.140)$ or Umbra $(P=0.413)$ were present.

Both anurans exhibited predator-induced spatial avoidance (Table 1, Fig. 2). The univariate analysis of activity and the subsequent mean comparisons indicated that wood frogs spatially responded only to Anax $(P=0.004)$ whereas leopard frogs spatially responded to both Anax $(P=0.003)$ and Umbra $(P<0.001)$. Comparing the two species, a higher proportion of leopard frogs were on the predator side of the tub in the absence of predators $(P=0.005)$ and in the presence of Anax $(P=0.005)$. The two anurans did not differ in their spatial distribution in the presence of Umbra $(P=0.886)$.

\section{Field experiment}

There were significant effects of pen treatment and prey species on survivorship and growth (MANOVA; Table 2). Only prey species were significant in the univariate analysis of survivorship. Averaged across all treatments, survivorship of wood frogs (mean $\pm 1 \mathrm{SE}$ ) was $78 \% \pm 4 \%$ compared to $63 \% \pm 4 \%$ for leopard frogs.

The univariate analysis of anuran growth indicated significant pen treatment and prey species effects as well as a significant interaction of the two factors (Table 2, Fig. 3). Compared to wood frogs reared alone, wood frogs reared with leopard frogs and no predators had nearly identical growth $(P=0.385)$. When Anax were added, wood frog growth was significantly less than wood frogs reared alone (a $22 \%$ reduction; $P=0.036$ ) but not different from the competition-no predator treatment (a $17 \%$ reduction; $P=0.170$ ). The competition-Umbra treatment and the competition-Anaxplus-Umbra treatment both reduced wood frog growth compared to wood frogs reared in the competition-no predator treatment (a 22\% decline, $P=0.005$; and a $42 \%$ decline, $P<0.001$; respectively).

Leopard frog growth rate also was affected by the

FIG. 3. Growth rates of larval leopard frogs and wood frogs when reared alone (no competition), together (competition), and together in the presence of different caged predators. Data are means $\pm 1 \mathrm{SE}$, and the variation around the mean includes significant block effects.

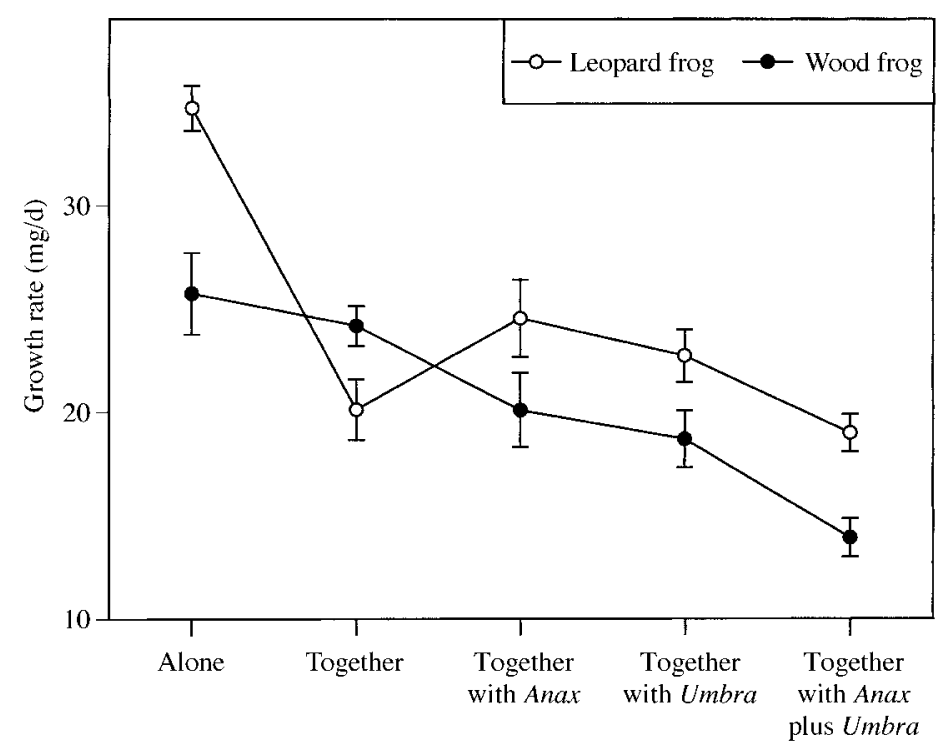


TABLE 3. Results from the MANOVA of larval wood frog and leopard frog morphological responses to spatial blocks and treatments imposed on them in pond enclosures.

\begin{tabular}{|c|c|c|c|c|c|c|c|}
\hline \multirow{3}{*}{$\begin{array}{l}\text { A. Univariate tests } \\
\text { Source }\end{array}$} & \multirow[b]{3}{*}{ df } & \multicolumn{6}{|c|}{ Body } \\
\hline & & \multicolumn{2}{|c|}{ Depth } & \multicolumn{2}{|c|}{ Length } & \multicolumn{2}{|c|}{ Width } \\
\hline & & $F$ & $P$ & $F$ & $P$ & $F$ & $P$ \\
\hline Block & 3,23 & 5.43 & 0.006 & 1.45 & 0.255 & 7.47 & 0.001 \\
\hline Species & 1,23 & 2.22 & 0.149 & 49.2 & $<0.001$ & 62.3 & $<0.001$ \\
\hline Treatment & 4,23 & 1.07 & 0.394 & 6.90 & $<0.001$ & 0.71 & 0.595 \\
\hline Species $\times$ Treatment & 4,10 & 0.77 & 0.558 & 0.41 & 0.780 & 1.05 & 0.401 \\
\hline \multicolumn{8}{|l|}{ B. Multivariate tests } \\
\hline Source & & \multicolumn{2}{|c|}{ df } & \multicolumn{2}{|c|}{ Wilks' $F$} & \multicolumn{2}{|c|}{$P$} \\
\hline Block & & \multicolumn{2}{|c|}{27,44} & \multicolumn{2}{|c|}{1.83} & \multicolumn{2}{|c|}{0.037} \\
\hline Species & & \multirow{2}{*}{\multicolumn{2}{|c|}{9,15}} & \multicolumn{2}{|c|}{7.14} & \multicolumn{2}{|c|}{$<0.001$} \\
\hline Treatment & & & 36,57 & \multicolumn{2}{|c|}{1.95} & \multicolumn{2}{|c|}{0.011} \\
\hline Species $\times$ Treatment & & \multicolumn{2}{|c|}{36,57} & \multicolumn{2}{|c|}{1.05} & \multicolumn{2}{|c|}{0.426} \\
\hline
\end{tabular}

pen treatments (Table 2, Fig. 3). Compared to leopard frogs reared alone, leopard frogs reared with wood frogs and no predators suffered a $42 \%$ decline in growth $(P<0.001)$. However, when Anax were added, leopard frog growth increased $22 \%(P=0.050)$ compared to the competition-no predator environment! Umbra caused leopard frog growth to be intermediate to that of the competition-no predator treatment and the Anax treatment and did not differ from either $(P>0.15)$. The presence of both predators decreased leopard frog growth by $23 \%$ compared to the Anax treatment ( $P=$ $0.006)$ and by $16 \%$ compared to the Umbra treatment $(P=0.018)$. The significant interaction between prey species and pen treatment was caused by the reversal in relative growth rates of wood frogs and leopard frogs in the competition-no predator treatment relative to the other treatments (Fig. 3)

The ANOVA of total biomass production exhibited a significant treatment effect $\left(F_{5,13}=5.1, P=0.008\right.$;

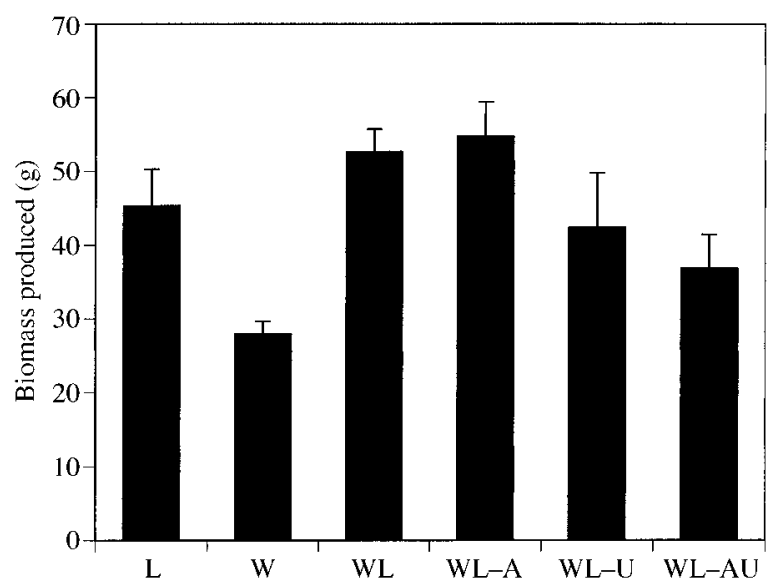

FIG. 4. Total biomass produced per pen by wood frogs (W) and leopard frogs (L) when reared alone, together (WL), together in the presence of Anax (WL-A), together in the presence of Umbra (WL-U), and together in the presence of both Anax plus Umbra (WL-AU). Data are means +1 SE.
Fig. 4) but no block effect $\left(F_{3,13}=1.6, P=0.228\right)$. Mean comparisons indicated that there was a higher production of leopard frog biomass than wood frog biomass when each species was reared alone $(P=$ $0.014)$. When the two species were reared together without predators, total production was not significantly different from leopard frogs reared alone $(P=$ 0.256). The addition of either Anax or Umbra did not significantly alter total production compared to the competition-no predator treatment $(P=0.581$ and $P$ $=0.119$, respectively). Biomass production in the presence of Anax plus Umbra was significantly lower than the competition-no predator treatment $(P=0.032)$.

The pen treatments and prey species had significant multivariate effects on anuran morphology. Univariate tests identified the specific dimensions that were affected (Table 3, Fig. 5). In the presence of competition and no predators, both wood frogs and leopard frogs developed wider mouths than when either species was reared alone $(P<0.001)$; leopard frogs increased their mouth width by $5 \%$ while wood frogs increased their mouth width by $10 \%$. Both prey species also tended to develop longer mouths; however, the univariate test across all treatments was not significant $(P=0.097)$. The other trait affected by competition was tail length. While there was a significant main effect of pen treatment on tail length, the treatment-by-species interaction test suggested that the two prey altered their tail length differently. In separate analyses by species, wood frogs developed a $3 \%$ longer tail when competitors were added (univariate main effect, $P<0.001$; mean comparison test of wood frogs alone vs. wood frogs under competition without predators, $P=0.005$ ) but leopard frogs did not significantly alter their tail length (univariate main effect, $P=0.790$ ). Thus, the addition of interspecific competition (without predators) induced leopard frogs to develop a relatively small increase in mouth size and wood frogs to develop a relatively large increase in mouth size and a slightly longer tail. 
TABle 3. Extended.

\begin{tabular}{|c|c|c|c|c|c|c|c|c|c|c|c|}
\hline \multicolumn{4}{|c|}{ Mouth } & \multicolumn{4}{|c|}{ Tail } & \multicolumn{4}{|c|}{ Muscle } \\
\hline \multicolumn{2}{|c|}{ Length } & \multicolumn{2}{|c|}{ Width } & \multicolumn{2}{|c|}{ Depth } & \multicolumn{2}{|c|}{ Length } & \multicolumn{2}{|c|}{ Depth } & \multicolumn{2}{|c|}{ Width } \\
\hline$F$ & $P$ & $F$ & $P$ & $F$ & $P$ & $F$ & $P$ & $F$ & $P$ & $F$ & $P$ \\
\hline 2.77 & 0.065 & 1.97 & 0.147 & 10.3 & $<0.001$ & 5.48 & 0.006 & 0.81 & 0.506 & 1.71 & 0.192 \\
\hline 12.3 & 0.002 & 91.6 & $<0.001$ & 5.04 & 0.035 & 165 & $<0.001$ & 7.33 & 0.013 & 1.43 & 0.244 \\
\hline 2.23 & 0.097 & 6.62 & 0.001 & 6.86 & $<0.001$ & 3.13 & 0.034 & 0.90 & 0.539 & 0.75 & 0.571 \\
\hline 1.26 & 0.316 & 0.89 & 0.487 & 0.21 & 0.932 & 1.96 & 0.135 & 1.35 & 0.282 & 0.55 & 0.698 \\
\hline
\end{tabular}

Univariate tests and mean comparisons also indicated that the larval anurans altered their morphology when caged predators were added to the competition environment (Table 3, Fig. 5). Compared to the competition-no predator treatment, both wood frogs and leopard frogs developed deeper tails in the presence of Anax $(P=0.001)$, Umbra $(P=0.036)$, and Anax plus Umbra $(P<0.001)$. The tadpoles simultaneously de-
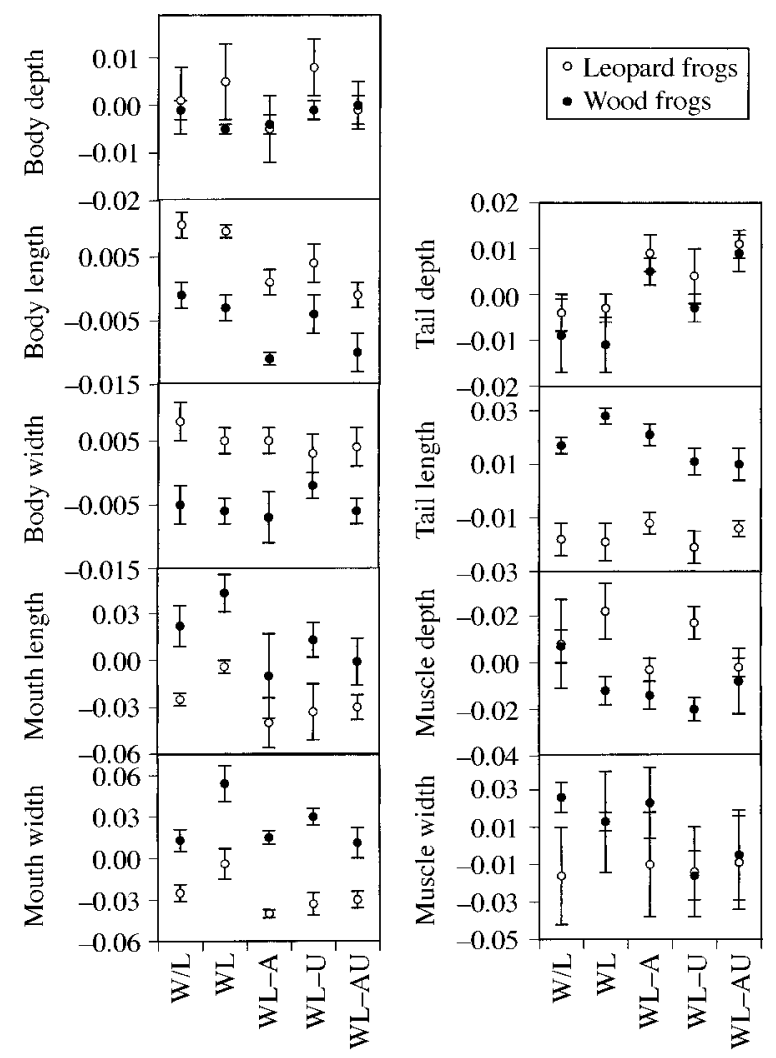

FIG. 5. The relative morphology of wood frogs and leopard frogs reared under five different treatments in pond enclosures: alone (W or L), in the presence of competitors (WL), in the presence of competitors and Anax (WL-A), in the presence of competitors and Umbra (WL-U), and in the presence of competitors and Anax plus Umbra. (WL-AU). Differences in overall body size are removed prior to analysis. (Data are residual lengths, widths, and depths following a regression of log-transformed distances against log-transformed body size.) Data are means $\pm 1 \mathrm{SE}$, and the variation around the mean includes significant block effects. veloped shorter bodies in the presence of Anax $(P=$ $0.004)$ and Anax plus Umbra $(P=0.004)$ but not in the presence of Umbra alone $(P=0.226)$. Mouth width in both anurans was reduced in the presence of all three predator treatments compared to the competition-no predator treatment $(P<0.003)$ and was not different from the mouth widths of each prey when reared alone $(P>0.2)$. The longer tail produced in the competitionno predator environment was reduced when predators were present. The decrease was not significant when Anax were present $(P=0.261)$ but was significant when Umbra $(P<0.001)$ or Anax plus Umbra were present $(P<0.001)$. Anax and Umbra induced tail lengths that were not different than when wood frogs were reared alone $(P>0.05)$ while Anax plus Umbra induced a tail that was shorter than when wood frogs were reared alone $(P=0.015)$. The remaining morphological traits were unaffected by the predators.

\section{Discussion}

The nonlethal presence of predators can reverse the relative outcome of competition between prey without affecting the density of either prey. Wood frogs and leopard frogs were competing in the field experiment and the response to competition was asymmetric; wood frog growth was unaffected by competition whereas leopard frog growth was greatly reduced. Past studies of competition between wood frogs and leopard frogs have found that relative growth of the two species can vary with experimental conditions. Werner (1992a) and Relyea (unpublished data) both found that when the species were reared under laboratory conditions, leopard frogs suppressed the growth rate of wood frogs. In contrast, Werner and Glennemeier (1999) and the present study have found that when the species were reared in pens placed in natural ponds, wood frogs suppressed the growth rate of leopard frogs. Further, DeBenedictis (1974) found competition between the anurans in a natural pond to be nonexistent in one year and symmetric the following year.

Predator presence reversed the relative growth advantage that wood frogs had over leopard frogs in this study. Given that the predators were caged and could not affect prey density, the change in competitive outcome must have arisen through predator-induced changes in prey traits which, in turn, changed the nature 
of the interaction between the prey and their food resources. This is a trait-mediated indirect effect. The change in competitive outcome also altered the biomass distribution between the two prey. Total biomass production did not differ among the competition treatments with no predators, Anax, and Umbra, but wood frogs produced a larger fraction of the biomass (presumably by harvesting a larger fraction of the food) when competing in the absence of the predators whereas leopard frogs produced a larger fraction of the biomass when competing in the presence of Anax or Umbra. Thus, the mere presence of a caged predator altered the relative outcome of competition between larval wood frogs and leopard frogs and this effect apparently was mediated through resources. That is, the presence of the predators altered some trait(s) of the wood frogs which made wood frogs harvest less resources, having a positive effect on the resource availability, and a positive indirect effect on the competing leopard frogs. In amphibians, decreased growth is associated with smaller size at age of first reproduction, lower survivorship in the terrestrial stage, and increased susceptibility to pond drying in the larval stage (Berven and Gill 1983, Smith 1983, Newman 1988, Semlitsch et al. 1988). Thus, these changes in growth experienced by the wood frogs and leopard frogs should directly affect their fitness.

The reversal of prey competition through direct effects of predation is well documented (Tansley and Adamson 1925, Jones 1933, Brooks and Dodson 1965, Paine 1966, Hall et al. 1970, Lubchenco 1978) but reversal through trait-mediated indirect effects is novel. A few investigators of trait-mediated indirect effects have demonstrated that predators can affect competition between prey but have not demonstrated a reversal of competitive outcome. In two studies using larval anurans (Werner and Anholt 1996, Peacor and Werner 1997), researchers found that small green frog larvae (which were vulnerable to predation) reduced their foraging activity, and therefore growth, in response to the predators while large bullfrog larvae (which were invulnerable to predation) did not respond to predators and experienced increased growth due to the increase in resources. In the current study, both prey were small and vulnerable to predation; thus, the effect of the predators was not unidirectional from predator to prey to resources to competitor. Rather, the predator affected the traits of both prey so the indirect effect on the two competing prey through their common resource was bidirectional.

Investigating the mechanisms driving the trait-mediated indirect effect requires an understanding of the determinants of relative competitive ability between the two species of larval anurans. Behavior is one trait that often has been invoked as a mechanism determining relative competitive ability. Typically, individuals that are more active and exhibit less spatial avoidance of predators garner resources at a proportionally greater rate (Sih 1987, Lima and Dill 1990, Werner 1992b, Werner and Anholt 1993, Relyea and Werner 1999). In this study, however, the trait-mediated indirect effects on anuran growth were not predictable from the behavioral responses that I observed in the laboratory. If we assume that the activity observed in the laboratory under different predator environments is qualitatively similar to activity in the field when competing under different predator environments (i.e., excluding the treatments of each species alone), one would predict that in the absence of predators wood frogs would grow faster than leopard frogs because they are the more active species. This prediction is supported. In the presence of Anax, overall growth should be lower for both species, but wood frogs should still enjoy higher relative growth than leopard frogs. In the presence of Umbra, one would expect that overall growth would decline even further but leopard frogs would tend to have higher relative growth than wood frogs. The second and third predictions were not supported; wood frogs did not grow faster than leopard frogs in the presence of Anax and growth did not decline more with Umbra compared to Anax. I did not evaluate the effect of competitors on the behavior of the anurans, but past investigators have shown that activity level commonly increases with competition (Horat and Semlitsch 1994, Anholt et al. 1996, Peacor and Werner 1997).

If spatial avoidance and a concomitant reduction in access to resources were the mechanism responsible for the observed growth in the field, one would expect field patterns of growth to be related to the magnitudes of spatial avoidance. In the presence of Anax, one would expect growth to decline but leopard frogs would exhibit higher relative growth than wood frogs. In the presence of Umbra, overall growth would still be reduced but growth should be similar between the two prey species. The latter prediction was not observed in the field experiment; leopard frogs grew faster than wood frogs in the presence of Umbra. Obviously, the laboratory and field experiments differed widely in experimental conditions, including the more natural and larger experimental units in the field, the presence of three individuals of each predator species in the field compared to a single individual in the laboratory, and the presence of interspecific competitors. Thus, a lack of congruence between behavioral responses in the laboratory and growth in the field might be attributable to differences in experimental conditions including prey and predator densities, water turbidity, and habitat complexity.

A second possible mechanism for the trait-mediated indirect effect is the change in larval morphology. The lack of a growth response by wood frogs when leopard frogs were added might lead one to conclude that wood frogs were unaffected by interspecific competition. However, wood frogs under competition exhibited a $10 \%$ increase in mouth width and $3 \%$ increase in tail length in comparison to those reared alone. In com- 
parison, leopard frogs increased their mouth width by $5 \%$ and did not change their tail length. If a longer tail and greater increase in mouth width provided a competitive advantage to the wood frog, then decreasing these traits should reverse the relative growth rates between the two competitors. The addition of predators decreased mouth width for both anurans and decreased tail length for wood frogs (although only the Umbra, and Anax plus Umbra treatments were significant). Concomitantly, there was a decrease in relative growth for wood frogs. This correlative evidence suggests that morphological changes drove the trait-mediated indirect effect on prey growth.

It is unclear whether or not the competitor-induced change in morphology is an adaptive response. Because the tail is used during tadpole foraging to swim and force the tadpole's rasping mouth against substrates, a longer tail might increase the force on the scraping denticles. This increased force could permit wood frog tadpoles to scrape a type of periphyton that is more resistant to harvest or to harvest periphyton more efficiently. The increased mouth width observed in both anurans provides a wider scraping surface area which also could result in more efficient foraging. The $10 \%$ increase in mouth width for wood frogs was relatively large and may be the primary cause of faster growth in wood frogs when competing with leopard frogs in the absence of predators. The smaller mouth change in leopard frogs (5\%) may have caused their slower growth rate when competing with wood frogs in the absence of predators.

An alternative explanation for the morphological changes is that they are simply allometric changes in morphology caused by changes in growth rate and body size. In the case of wood frogs, the addition of interspecific competitors (without predators) did not have any effect on wood frog mass, yet the mouth still became relatively wider and the tail became relatively longer. This suggests that the competitor-induced changes in morphology were not due to allometric effects. Further, Relyea and Werner (2000) have followed predator-induced morphology over ontogeny and have demonstrated that predator-induced changes in morphology cannot be explained by allometry.

While the morphological responses may explain the changes in relative growth among treatments, they do not explain why overall growth (biomass production) declined when both predator species were present. Both anuran species grew more slowly when two species of predators were present than when one of the predators was present. Morphology in the presence of Anax plus Umbra did not differ from the trait values with either Anax or Umbra alone. Since I have no behavioral data on the activity and spatial distribution of the tadpoles in the presence of both predators, I cannot rule out behavioral mechanisms as an explanation. The larvae may have reduced activity to more extreme levels in the presence of both predators.
There appear to be few other examples of competitorinduced morphological plasticity in animals, most likely due to a lack of investigation rather than a lack of occurrence (see citations in Introduction). However, there are cases of animals altering their morphology in response to different diets (Bernays 1986, Meyer 1987, Wainwright et al. 1991, Reilly et al. 1992); thus, if competition alters the type of food available, then these cases would also represent competitor-induced plasticity. This study, as well as subsequent studies (Relyea, unpublished data), suggests that competitor-induced morphological plasticity might be more common than we currently appreciate, particularly in tadpoles, and deserves increased attention.

In addition to reducing tail length and mouth width, predators also induced other changes in tadpole morphology that support findings from previous studies conducted in more artificial environments. The increase in tail depth and decrease in body length in the presence of aeshnid dragonflies has been found in other studies of wood frogs and leopard frogs (Van Buskirk and Relyea 1998, Relyea and Werner 2000) as well as in chorus frogs and gray tree frogs (Smith and Van Buskirk 1995, McCollum and Van Buskirk 1996, McCollum and Leimberger 1997, Van Buskirk et al. 1997). This plastic response to aeshnids is maintained by selection; tadpoles with deeper tail fins and shorter bodies survive aeshnid predation better whereas tadpoles with the shallow tail fins and long bodies grow faster in aeshnidfree environments (Van Buskirk et al. 1997, Van Buskirk and Relyea 1998). Thus, this study provides further support for predator-induced morphological changes in larval anurans and documents their occurrence in a more natural experimental setting.

This study illustrates the potential importance of morphological plasticity in affecting interspecific interactions. Given our growing number of examples of morphological plasticity in numerous taxa, we need to consider the role of both behavioral and morphological plasticity in shaping the structure and composition of ecological communities. We will likely discover that both types of traits are important and that they interact to affect an individual's performance. Taking this more extensive, multi-trait approach will undoubtedly shed new light on the role of trait-mediated indirect effects in ecological communities.

\section{ACKNOWLEDGMENTS}

I thank Peter Eklöv, Andy McCollum, Scott Peacor, Josh Van Buskirk, Earl Werner, and Kerry Yurewicz for assistance with the field work and Ronald Nussbaum and Richard Alexander for providing access to the Edwin S. George Reserve. I also thank Scott Peacor and Earl Werner for comments on this manuscript. This work was supported by University of Michigan research grants and NSF grant DEB-9119948.

\section{Literature Cited}

Abrams, P. A. 1983. Arguments in favor of higher-order interactions. American Naturalist 121:887-891.

Abrams, P. A. 1995. Implications of dynamically variable traits for identifying, classifying, and measuring direct and 
indirect effects in ecological communities. American Naturalist 146:112-134.

Altmann, J. 1974. Observational study of behavior: sampling methods. Behaviour 49:227-267.

Anholt, B. R., D. K. Skelly, and E. E. Werner. 1996. Factors modifying antipredator behavior in larval toads. Herpetologica 52:301-313.

Bernays, E. A. 1986. Diet-induced head allometry among foliage-chewing insects and its importance for graminivores. Science 231:495-497.

Berven, K. A., and D. E. Gill. 1983. Interpreting geographic variation in life-history traits. American Zoologist 23:8597.

Bookstein, F. L. 1991. Morphometric tools for landmark data. Cambridge University Press, Cambridge, UK.

Brooks, J. L., and S. I. Dodson. 1965. Predation, body size, and composition of plankton. Science 150:28-35.

Collins, J. P., and D. W. Pfennig. 1993. Kinship affects morphogenesis of cannibalistic tadpoles. Nature 362:836-838.

Collins, J. P., and H. M. Wilbur. 1979. Breeding habits and habitats of the amphibians of the Edwin S. George Reserve, Michigan, with notes on the local distribution of fishes. Occasional Papers Museum of Zoology, University of Michigan, Number 686:1-34.

DeBenedictis, P. A. 1974. Interspecific competition between of Rana pipiens and Rana sylvatica: an experimental field study. Ecological Monographs 44:129-151.

Diehl, S., and P. Eklöv. 1995. Effects of piscivore-mediated habitat use on resources, diet, and growth of perch. Ecology 76:1712-1726.

Hall, D. J., W. E. Cooper, and E. E. Werner. 1970. An experimental approach to the production dynamics and structure of freshwater animal communities. Limnology and Oceanography 15:839-928.

Harvell, C. D. 1990. The ecology and evolution of inducible defenses. Quarterly Review of Biology 65:323-340.

Havel, J. E. 1987. Predator-induced defenses: a review. Pages 263-278 in W. C. Kerfoot and A. Sih, editors. Predation: direct and indirect impacts on aquatic communities. University Press of New England, Hanover, New Hampshire, USA.

Horat, P., and R. D. Semlitsch. 1994. Effects of predation risk and hunger on the behaviour of two species of tadpoles. Behavioral Ecology and Sociobiology 34:393-401.

Hunter, M. D., and P. W. Price. 1992. Playing chutes and ladders: heterogeneity and the relative roles of bottom-up and top-down forces in natural communities. Ecology 73 : $724-732$.

Jones, M. G. 1933. Grassland management and its influence on the sward. Empire Journal of Experimental Agriculture 1:43-367.

Karban, R., and I. T. Baldwin. 1997. Induced responses to herbivory. University of Chicago Press, Chicago, Illinois, USA.

Kats, L. B., J. W. Petranka, and A. Sih. 1988. Antipredator defenses and the persistence of amphibians larvae with fishes. Ecology 69:1865-1870.

Kruse, K. C., and M. G. Francis. 1977. A predation deterrent in larvae of the bullfrog, Rana catesbeiana. Transactions American Fisheries Society 106:248-252.

Lima, S. L., and L. M. Dill. 1990. Behavioral decisions made under the risk of predation: a review and prospectus. Canadian Journal of Zoology 68:619-640.

Lubchenco, J. 1978. Plant species diversity in a marine intertidal community: importance of herbivore food preference and algal competitive abilities. American Naturalist 112:23-39.

McCollum, S. A., and J. D. Leimberger. 1997. Predator-induced morphological changes in an amphibian: predation by dragonflies affects tadpole shape and color. Oecologia 109:615-621.

McCollum, S. A., and J. Van Buskirk. 1996. Costs and benefits of a predator-induced polyphenism in the gray treefrog Hyla chrysocelis. Evolution 50:583-593.

Meyer, A. 1987. Phenotypic plasticity and heterochrony in Cichlasoma managuense (Pisces, Cichlidae) and their implications for specialization in cichlid fishes. Evolution 41: $1357-1369$.

Newman, R. A. 1988. Adaptive plasticity in development of Scaphiopus couchii tadpoles in desert ponds. Evolution 42: 774-783.

Paine, R. T. 1966. Food web complexity and species diversity. American Naturalist 100:65-75.

Peacor, S. D., and E. E. Werner. 1997. Trait-mediated indirect interactions in a simple aquatic food web. Ecology 78: $1146-1156$.

Persson, L., and P. Eklöv. 1995. Prey refuges affecting interactions between piscivorous perch and juvenile perch and roach. Ecology 76:70-81.

Petranka, J. W., L. B. Kats, and A. Sih. 1987. Predator-prey interactions among fish and larval amphibians: use of chemical cues to detect predatory fish. Animal Behavior 35:420-425.

Pfennig, D. W. 1992a. Polyphenism in spadefoot toad tadpoles as a locally adjusted evolutionary stable strategy. Evolution 46:1408-1420.

Pfennig, D. W. 1992b. Proximate and functional causes of polyphenism in an anuran tadpole. Functional Ecology 6: 167-174.

Power, M. E. 1992. Top-down and bottom-up forces in food webs: do plants have primacy? Ecology 73:733-746.

Reilly, S. M., G. V. Lauder, and J. P. Collins. 1992. Performance consequences of a trophic polymorphism: feeding behavior in typical and cannibal phenotypes of Ambystoma tigrinum. Copeia 1992:672-679.

Relyea, R. A., and E. E. Werner. 1999. Quantifying the relation between predator-induced behavioral responses and growth performance in larval anurans. Ecology 80:21172124.

Relyea, R. A., and E. E. Werner. 2000. Morphological plasticity of four larval anurans distributed along an environmental gradient. Copeia 2000:178-190.

Schmitz, O. J., A. P. Beckerman, and K. M. O’Brien. 1997. Behaviorally mediated trophic cascades: effects of predation risk on food web interactions. Ecology 78:1388-1399.

Semlitsch, R. D., D. C. Scott, and J. H. K. Pechmann. 1988. Time and size at metamorphosis related to adult fitness in Ambystoma talpoideum. Ecology 69:184-192.

Sih, A. 1987. Predators and prey lifestyles: an evolutionary and ecological overview. Pages 203-224 in W. C. K. Sih, editor. Predation: direct and indirect impacts on aquatic communities. University Press of New England, Hanover, New Hampshire, USA.

Skelly, D. K. 1992. Field evidence for a cost of behavioral antipredator response in a larval amphibian. Ecology 73: 704-708.

Skelly, D. K., E. E. Werner, and S. A. Cortwright. 1999. Logterm distributional dynamics of a Michigan amphibian assemblage. Ecology 80:2326-2338.

Smith, D. C. 1983. Factors controlling tadpole populations of the chorus frog (Pseudacris triseriata) on Isle Royale, Michigan. Ecology 64:501-510.

Smith, D. C., and J. Van Buskirk. 1995. Phenotypic design, plasticity, and ecological performance in two tadpole species. American Naturalist 145:211-233.

Strong, D. R. 1992. Are trophic cascades all wet? differentiation and donor-control in speciose ecosystems. Ecology 73:747-754.

Tansley, A. G., and R. S. Adamson. 1925. The chalk grass- 
lands of the Hampshire-Sussex border. III. Studies of the vegetation of the British chalk. Journal of Ecology 5:173179.

Turner, A. M., and G. G. Mittelbach. 1990. Predator avoidance and community structure: interactions among piscivores, planktivores, and plankton. Ecology 71:2241-2254.

Van Buskirk, J., S. A. McCollum, and E. E. Werner. 1997. Natural selection for environmentally-induced phenotypes in tadpoles. Evolution 52:1983-1992.

Van Buskirk, J., and R. A. Relyea. 1998. Natural selection for phenotypic plasticity: predator-induced morphological responses in tadpoles. Biological Journal of the Linnean Society 65:301-328.

Wainwright, P. C., C. W. Osenberg, and G. C. Mittelbach. 1991. Trophic polymorphism in the pumpkinseed sunfish (Lepomis gibbosus): environmental effects on ontogeny. Functional Ecology 5:40-55.

Werner, E. E. 1992a. Competitive interactions between wood frog and northern leopard frog larvae: the influence of size and activity. Copeia 1992:26-35.
Werner, E. E. 1992b. Individual behavior and higher-order species interactions. American Naturalist 140:S5-S32.

Werner, E. E., and B. R. Anholt. 1993. Ecological consequences of the trade-off between growth and mortality rates mediated by foraging activity. American Naturalist 142: 242-272.

Werner, E. E., and B. R. Anholt. 1996. Predator-induced behavioral indirect effects: consequences to competitive interactions in anuran larvae. Ecology 77:157-169.

Werner, E. E., and K. S. Glennemeier. 1999. The influence of forest canopy cover on the breeding pond distribution of several amphibian species. Copeia 1999:1-12.

Werner, E. E., and M. A. McPeek. 1994. Direct and indirect effects of predators on two anuran species along an environmental gradient. Ecology 75:1368-1382.

Wissinger, S., and J. McGrady. 1993. Intraguild predation and competition between larval dragonflies: direct and indirect effects on shared prey. Ecology 74:207-218.

Wootton, J. T. 1992. Indirect effects, prey susceptibility, and habitat selection: impacts of birds on limpets and algae. Ecology 73:981-991. 